\title{
IMPACT OF DIFFERENT DOSING STRATEGIES OF NIVOLUMAB IN PATIENTS WITH SOLID TUMORS: ITALIAN SINGLE CENTER ANALYSIS
}

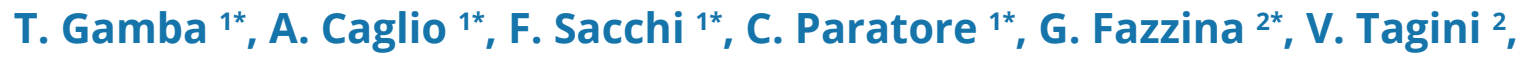 \\ M. Bellero ${ }^{2}$, S. Masucci ${ }^{2}$, F. Vignani ${ }^{1}$, G. Lacidogna ${ }^{1}$, C. Zichi ${ }^{1}$, G. Aimar ${ }^{1}$, \\ D. Marino ${ }^{1}$, E. Sperti ${ }^{1}$, A. Gasco ${ }^{2}$, M. Di Maio ${ }^{1}$ \\ ${ }^{1}$ Department of Oncology, University of Turin, Ordine Mauriziano Hospital, Turin, Italy \\ ${ }^{2}$ Hospital Pharmacy, Ordine Mauriziano Hospital, Turin, Italy \\ ${ }^{*}$ Contributed equally
}

\section{CORRESPONDING AUTHOR:}

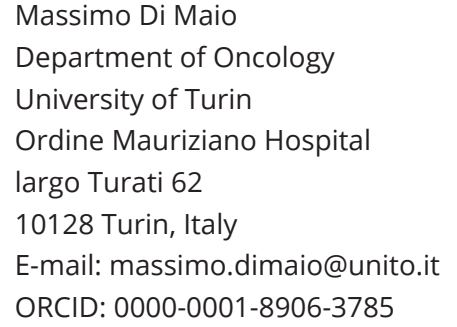

\section{ABSTRACT}

Nivolumab is approved and reimbursed by Italian Drug Agency (AIFA) in several tumors, including non-small cell lung cancer, head \& neck cancer and renal cell cancer. In May 2018, the original schedule ( $3 \mathrm{mg} / \mathrm{kg}$ every 2 weeks) - used in pivotal clinical trials demonstrating treatment efficacy - was replaced by a flat dose ( $240 \mathrm{mg}$ every 2 weeks). Aim of this study was to identify the most cost-effective dosing strategy of nivolumab in a real-world setting. The primary endpoint of this analysis was the difference of nivolumab costs between the real scenario based on data from our hospital, and the hypothetical expenditure according to different simulated strategies of nivolumab dosing. The secondary endpoint was to report the economic savings associated with "drug day" and dose rounding strategies in the same scenario.

We collected data from patients treated with nivolumab at Mauriziano Umberto I Hospital in Turin, from January 2019 to August 2020. We analysed different dosing strategies (flat dose, weightbased-dose and hybrid), computed the cost of each one and compared them to the real expense. In addition, we performed sensitivity analysis modifying nivolumab price and mean patients' body weight. Among different dosing strategies, hybrid strategy was the most cost-effective approach, with a $11.7 \%$ saving compared to the real expense. Dose rounding and vial sharing minimized the drug waste. Applying our data to a hypothetical population of 1000 patients, savings associated with hybrid strategy could have covered 1423 additional treatment 
cycles. Hybrid strategy was confirmed the mostcost effective in all sensitivity analyses.

Hybrid strategy was the most cost-effective strategy compared to the other dosing strategies (and compared to the real scenario, mainly based on fixed dose). Furthermore, this analysis demonstrated the importance of waste minimization policies, decreasing oncologic therapies costs.

\section{KEY WORDS}

Nivolumab; dosing strategies; flat-dose;

hybrid strategy; cost-effective.

\section{IMPACT STATEMENT}

This analysis compared the economic impact of different dosing strategies of nivolumab, based on the results obtained in a single Italian center, and showing hybrid dose strategy as the most cost-effective one.

mal regimen to guarantee the maximum efficacy and tolerability in different malignancies and to be tested in the following clinical trials. The use of a body-weight based schedule was justified by the intention of reducing variability in both drug distribution and elimination between patients.

In September 2016, US Food and Drug Administration (FDA) has modified the dosage regimen to the flat-dose of $240 \mathrm{mg}$ Q2W (which is the equivalent dose for patients weighing $80 \mathrm{~kg}$ ), followed by European Medicines Agency (EMA) in 2018. The transition to a fixed dose of nivolumab took place to allow a shorter drug preparation time, an easier administration and easier medical prescription of treatment regimens, and led to a waiting time reduction for patients (10). Following EMA decision, in May 2018 adoption of fixed dose was recommended by Italian Drug Agency. Consequently, all patients who started treatment after May 2018 received fixed dose, while patients already on treatment continued with the previous dosing strategy ( $3 \mathrm{mg} / \mathrm{kg}$ ).

Several PD1/PD-L1 inhibitors, such as nivolumab, pembrolizumab and avelumab, were initially approved by regulatory agencies with a body weightbased dose, according to the standard practice of correlating drug clearance to body surface area. Nevertheless, several dose-findings studies have shown similar efficacy and safety between different dosing regimens through the assessment of pharmacokinetics data, exposure-response relationships and tolerability results $(11,12)$. Flat dose and body weight-based dose provide similar distribution and drug exposure, within a similar range of pharmacokinetic variability, ensuring additional support for switching dosing regimen (13). With regard to 
nivolumab, previous dose-response and exposure-response analyses showed overlapping safety and efficacy results, from either $3 \mathrm{mg} / \mathrm{kg}$ Q2W or $240 \mathrm{mg}$ Q2W flat dose, which allows the use of flat dose as an effective therapeutic dosage for $>80 \mathrm{~kg}$ patients $(8,14-16)$. On the other side, pharmacodynamic trials has identified body weight-based dosing as the optimal regimen to provide the maximum efficacy and tolerability for several malignant disease $(8,9,17)$ and subsequently in nivolumab pivotal trials (2-5), justify this schedule for $<80 \mathrm{~kg}$ patients. However, several European and American studies have highlighted an increase in health expenditure with the adoption of flat dose. This discrepancy could be mainly attributed to the average weight of cancer patients in clinical practice, which is generally less than $80 \mathrm{~kg}$ (18-21). Several strategies have been proposed to reduce costs. Differently from flat dose, dose per kg of body weight, with different dose for each patient, is associated with a potential waste of drug. Waste minimization systems, such as the socalled "drug day", in which the drug is administered only on certain days of the week, allow the reuse of drug residues in vials. Furthermore, the dose rounding allows to round off the theoretical calculated dose using the available vial sizes and avoiding to open another vial for a minimal amount of drug. Among the strategies proposed to reduce costs, the hybrid dosing strategy (using $3 \mathrm{mg} / \mathrm{kg}$ in patients below $80 \mathrm{~kg}$ and flat dose with $80 \mathrm{~kg}$ and above) allows to use the more convenient dosing in each patient (22).

This analysis was conducted to compare the economic impact of different nivolumab dosing strategies: the flat dose adopted in May 2018 as the "official" dosing strategy (240 mg Q2W), versus the body weight-based dose, used for previous patients and adopted in the pivotal trials $(3 \mathrm{mg} / \mathrm{Kg}$ Q2W), versus the "hybrid" dosing strategy (consisting in the adoption of the $3 \mathrm{mg} / \mathrm{Kg}$ Q2W in patients with body weight $<80 \mathrm{~kg}$ and of the fixed dose 240 $\mathrm{mg}$ Q2W in patients with body weight $\geq 80 \mathrm{~kg}$ ).

The aim of this study was to identify the most cost-effective dosing strategy and quantifying the potential economic savings in a real-world setting.

\section{MATERIALS AND METHODS}

In this single-center retrospective analysis, we collected expense and clinical data from patients with 3 different tumor types (metastatic NSCLC, advanced RCC, platinum-refractory SCCHN) treated with nivolumab at Mauriziano Umberto I Hospital in Turin, from January 2019 to August 2020.

The primary endpoint of this analysis was to describe the difference, in terms of nivolumab consumption and nivolumab costs, between the real expense data based on data of our hospital, and the hypothetical expenditure according to different simulated strategies of nivolumab dosing, in order to identify the most cost-effective approach. The secondary endpoint was to report the economic savings allowed by "drug day" and dose rounding strategies in the same scenario.

The analysis is based on the real expense data of nivolumab at Mauriziano Umberto I Hospital. In addition, we estimated the hypothetical consumption and expenditure of nivolumab in a population of $1000 \mathrm{pa}$ tients, using three different dosing strategies:

- body weight-based dose: $3 \mathrm{mg}$ per kilogram of patient body weight, every 2 weeks;

- flat dose strategy: 240 mg for every administration, regardless of weight, every 2 weeks;

- hybrid strategy: body weight-based dose for patients with body weight below $80 \mathrm{~kg}$, and flat dose for patients with body weight $80 \mathrm{~kg}$ and above.

For the simulated scenarios, we assumed that the distribution of patients' characteristics (in particular, in terms of body weight) in the hypothetical population of 1000 patients is the same we observed in the series of patients treated at Mauriziano Umberto I Hospital. In addition, we assumed for our model the same proportion of patients still receiving the $\mathrm{mg} / \mathrm{kg}$ dose in the period considered for the analysis, having started treatment before the regulatory change in the drug schedule. Finally, we assumed that the impact of pharmacological characteristics (available size vials, "drug day", amount of dose rounding and drug wastes) is the same in our Institution and in the whole simulated population.

\section{Pharmaceutical characteristics}

Three different sizes of nivolumab vials were available: $4 \mathrm{ml}, 10 \mathrm{ml}$ and $24 \mathrm{ml}$. Each $\mathrm{ml}$ of solution contains $10 \mathrm{mg}$ of drug, and each vial contains an overfill. Consequently, vials of $4 \mathrm{~mL}, 10 \mathrm{~mL}$ and 24 $\mathrm{mL}$ contain $45 \mathrm{mg}, 110 \mathrm{mg}$ and $247 \mathrm{mg}$ of nivolum$a b$ respectively. While in the fixed dose strategy the total dose is coincident with the whole content of vials, in body weight-based dose and hybrid strategies, a variable amount of nivolumab wastage may occur, because more than one vial may be required to reach the total dose for patients and the amount of drug in vials may not exactly match the required 
dose. In clinical practice, it is allowed to round up dosages (dose rounding strategy) to reduce the drug waste, assuming that the minimal reduction in the dose does not impact treatment efficacy. Our hospital Pharmacy allows a rounding of nivolumab dosage within the $5 \%$ of the theoretical dose.

While flat dose strategy does not produce drug waste, drug residuals and correlated costs were calculated for weight-based dose and hybrid strategies. Drug day system is used in our center to handle and minimize wastes.

\section{SENSITIVITY ANALYSIS}

Univariate sensitivity analysis was performed to control uncertainty of economic evaluation and to allow the generalizability in a larger population. After base-cost analysis of nivolumab, we re-calculated the results of different dosing strategies holding all parameters but modifying 2 variables, in 4 alternative scenarios. In this economic model, two main variables were identified: the price of nivolumab and the body weight of patient. The nivolumab price has been reduced by 30\% from January 2020 in Italy. Until December 2019, the price of $1 \mathrm{mg}$ of nivolumab was $€ 11,1$ and the cost of one flat dose was $€ 2.664$. From January 2020, the price of $1 \mathrm{mg}$ has been reduced to $€ 7,69$, with a total amount of $€ 1.845,6$ for flat dose. Thus, we hypothesized two future scenarios with further $30 \%$ decreasing price compared to the current price: reduction of the current price from $€ 7,69$ to $€ 5,39$ (scenario I) and further reduction of $30 \%$ from $€ 5,39$ to $€ 3,77$ (scenario II). Regarding patient's body weight, in the study population we observed a large variety of weight-based dosages, from a minimal value of $130 \mathrm{mg}$ to a maximum dose of $255 \mathrm{mg}$. The average weight-based dose was 192,9 mg corresponding to a price of $€ 2.026,3$ in 2019 and $€ 1.403,8$ in 2020 . We then assumed two additional scenarios: scenario III considering a $5 \%$ increase in mean body weight and scenario IV considering a 5\% decrease in mean body weight.

\section{RESULTS}

\section{Baseline patient characteristics}

33 patients were included in the study: 6 with RCC, 8 patients with SCCHN and 19 with NSCLC (table I). Nearly all patients had advanced disease: 24 patients

\begin{tabular}{|c|c|c|}
\hline & $\begin{array}{c}\text { PATIENTS } \\
\text { CHARACTERISTICS }\end{array}$ & N PTS (\%) \\
\hline MEAN AGE & & $68,3 y$ \\
\hline SEX & $\begin{array}{l}\text { Male } \\
\text { Female }\end{array}$ & $\begin{array}{l}24(73) \\
9(27)\end{array}$ \\
\hline $\begin{array}{l}\text { PERFORMANCE } \\
\text { STATUS }\end{array}$ & $\begin{array}{l}\text { ECOG } 0 \\
\text { ECOG } 1 \\
\text { ECOG } 2\end{array}$ & $\begin{array}{l}8(24) \\
20(60) \\
4(12)\end{array}$ \\
\hline HISTOLOGY & $\begin{array}{l}\text { NSCLC } \\
\text { RCC } \\
\text { SCCHN }\end{array}$ & $\begin{array}{l}19(58) \\
6(18) \\
8(24)\end{array}$ \\
\hline STAGE & $\begin{array}{l}\text { Locally advanced } \\
\text { Metastatic disease }\end{array}$ & $\begin{array}{l}9(27) \\
24(73)\end{array}$ \\
\hline WEIGHT & $\begin{array}{l}\text { Average weight } \\
\geq 80 \mathrm{~kg} \\
<80->60 \mathrm{~kg} \\
\leq 60 \mathrm{~kg}\end{array}$ & $\begin{array}{l}69,5 \mathrm{~kg} \\
6(18) \\
17(53) \\
10(30)\end{array}$ \\
\hline NIVOLUMAB & $\begin{array}{l}\text { As } 2^{\text {nd }} \text { line } \\
\text { As } 3^{\text {rd }} \text { line }\end{array}$ & $\begin{array}{l}25(76) \\
7(21)\end{array}$ \\
\hline
\end{tabular}

Table I. Baseline patients' characteristics.

had metastatic disease and 9 a locally advanced disease not amenable for curative treatment.

The mean weight of patients included in the analysis was $69,5 \mathrm{~kg}$. Only 6 patients (18\%) had a body weight greater than or equal to $80 \mathrm{~kg}$, and most of the patients (53\%) had a body weight between 60 and $80 \mathrm{~kg}$.

In the study population, treatment with nivolumab was always administered as a subsequent line after the failure of previous therapy: 25 patients (76\%) as second line, $7(21 \%)$ as third line and one (3\%) as fourth line.

Regarding the nivolumab dose, about $70 \%$ of patients received flat dose and $30 \%$ received body weight-based dose. In fact, patients who had begun nivolumab before the regulatory recommendation of flat dose continued to receive nivolumab 3 mg/kg. Furthermore, from April 2020, new patients received the body weight dose due the approval of hybrid strategy by the Internal Pharmaceutical Commission of our Hospital.

We analysed the different alternative therapeutic strategies, computed the cost of each one and applied them to a hypothetical population of 1000 patients receiving nivolumab.

In the cost analysis, we estimated the potential expenditure for nivolumab for solid tumor treatment in the simulated population of 1000 patients using three different strategies (table II). This cost analysis 


\begin{tabular}{|c|c|c|c|}
\hline & \multicolumn{1}{|c|}{$\begin{array}{c}\Delta \% \\
\text { (VS REAL SCENARIO) }\end{array}$} & $\begin{array}{c}\Delta \text { N } \\
\text { (VS REAL SCENARIO) }\end{array}$ & $\begin{array}{c}\text { NIVOLUMAB EXPENSE } \\
\text { DATA IN 1000 PATIENTS }\end{array}$ \\
\hline REAL SCENARIO & - & - & $€ 21.786 .702,12$ \\
\hline FLAT DOSE STRATEGY & $+4,6$ & $+€ 1.002 .188,30$ & $€ 22.788 .890,42$ \\
\hline $\begin{array}{c}\text { BODY WEIGHT-BASED } \\
\text { STRATEGY }\end{array}$ & -9 & $-€ 1.960 .803,19$ & $€ 19.825 .898,93$ \\
\hline $\begin{array}{c}\text { HYBRID STRATEGY } \\
\text { HYRAT }\end{array}$ & $-11,7$ & $-€ 2.549 .044,15$ & $€ 19.237 .657,97$ \\
\hline
\end{tabular}

Table II. Nivolumab expense data.

\begin{tabular}{|c|l|l|l|}
\hline & \multicolumn{1}{|c|}{$\begin{array}{c}\Delta \% \\
\text { (VS REAL SCENARIO) }\end{array}$} & $\begin{array}{c}\Delta \mathbf{N} \\
\text { (VS REAL SCENARIO) }\end{array}$ & $\begin{array}{c}\text { NIVOLUMAB EXPENSE } \\
\text { DATA + WASTE COST } \\
\text { IN 1000 PATIENTS }\end{array}$ \\
\hline REAL SCENARIO & - & - & $€ 21.908 .343,94$ \\
\hline FLAT DOSE STRATEGY & $+4 \%$ & $+€ 876.333,76$ & $€ 22.784 .677,70$ \\
\hline $\begin{array}{c}\text { BODY WEIGHT-BASED } \\
\text { STRATEGY }\end{array}$ & $-8,3 \%$ & $-€ 1.818 .392,55$ & $€ 20.089 .951,39$ \\
\hline HYBRID STRATEGY & $-11 \%$ & $-€ 2.409 .917,83$ & $€ 19.498 .426,11$ \\
\hline
\end{tabular}

Table III. Nivolumab expense data (without waste optimization).

included waste minimization system: drug day vial sharing and dose rounding. For flat dose strategy, the potential expenditure would be $€ 22.788 .890,42$, increasing the total spending by $4,6 \%$ compared to the real scenario ( $+€ 1.002 .188,30)$. For body weightbased dose, the potential expenditure would be $€$ $19.825 .898,93$, with a saving of $9 \%(-€ 1.960 .803,19)$ compared to the real scenario. For hybrid strategy, the potential expenditure would be $€ 19.237 .657,97$, with a saving of $11.7 \%$ (- $€ 2.549 .044,15)$.

Consequently, hybrid strategy could reduce the amount of nivolumab consumed causing cost savings by about $3 \%$ compared to the weight-based strategy. According to the cost analysis, hybrid strategy was the most cost-effective in every comparison. If we hypothesize that, differently from our Hospital, all 1000 patients actually received the flat dose, the adoption of body-weight based strategy would allow a $13 \%$ saving ( $€ 2.962 .991,49)$, and the adoption of hybrid strategy would allow a $15.6 \%$ saving (€ 3.551.232,45).

We quantified the nivolumab waste and the corresponding cost during the observation period at Mauriziano Umberto I Hospital of Turin. Projecting these results into scenario population of 1000 patients, the cost of waste corresponded to $€$ $121.641,82$. The drug waste in the hybrid and body weight-based strategies would be larger than the real scenario by $105 \%$, corresponding to an absolute increase of $€ 249.365,72$. Flat dose would not create any drug waste, because of the administration of an entire vial per patient.

Transposing this result into a population of 1000 patients, the expenditure (excluding waste minimization policies, in order to estimate the waste impact) would have been $€ 21.908 .343,94$ (table III). There was no difference in drug waste between the hybrid and the body weight-based strategies. Indeed, the consumption and waste of nivolumab were the same in both strategies in patients with body weight less than $80 \mathrm{~kg}$. In patients $\geq 80 \mathrm{~kg}$, dosages of nivolumab were different, but the waste was similar due the using of dose rounding in body weight-based strategy. In the economic model of nivolumab expense data in a population of 1000 patients, hybrid strategy was the most cost-effective approach regardless wastage cost, saving € 2.409.917,83.

Although hybrid and body weight-based strategies were the most economic, they produced the largest amount of drug waste. However, the use of dose rounding and vial sharing minimized the drug left unutilized, thus drug waste could be considered close to zero. Therefore, hybrid strategy with cost minimization systems could save $€ 2.549 .044,15$ in 1000 pa- 


\begin{tabular}{c|c|c|c}
\hline $\begin{array}{c}\text { HYBRID STRATEGY SAVING } \\
\text { IN 1000 PATIENTS }\end{array}$ & $\begin{array}{c}\text { CURRENT PRICE } \\
\text { OF NIVOLUMAB }\end{array}$ & ADDITIONAL DRUG & ADDITIONAL CYCLES \\
\hline$€ 2.549 .044,15$ & $€ 7.69 / \mathrm{mg}$ & $331.475,18 \mathrm{mg}$ & 1423 cycles \\
\hline
\end{tabular}

Table IV. Additional amount and cycles of Nivolumab using the savings obtained with hybrid strategy.

\begin{tabular}{|c|c|c|c|c|c|c|}
\hline & \multicolumn{3}{|c|}{$€ 5,39 / \mathrm{MG}$} & \multicolumn{3}{|c|}{$€ 3,77 / M G$} \\
\hline & $\begin{array}{c}\Delta \% \\
\text { (COMPARED } \\
\text { TO REAL } \\
\text { SCENARIO) }\end{array}$ & $\begin{array}{c}\Delta \mathbf{N} \\
\text { (COMPARED TO } \\
\text { REAL SCENARIO) }\end{array}$ & $\begin{array}{l}\text { NIVOLUMAB } \\
\text { EXPENSE DATA } \\
\text { (SCENARIO I) } \\
\text { IN } 1000 \text { PATIENTS }\end{array}$ & $\begin{array}{c}\Delta \% \\
\text { (COMPARED } \\
\text { TO REAL } \\
\text { SCENARIO) }\end{array}$ & $\begin{array}{c}\Delta N \\
\text { (COMPARED } \\
\text { TO REAL } \\
\text { SCENARIO) }\end{array}$ & $\begin{array}{l}\text { NIVOLUMAB } \\
\text { EXPENSE DATA } \\
\text { (SCENARIO II) } \\
\text { IN } 1000 \\
\text { PATIENTS }\end{array}$ \\
\hline $\begin{array}{c}\text { REAL } \\
\text { SCENARIO }\end{array}$ & - & - & $€ 15.270 .523,33$ & - & - & $€ 10.680 .866,97$ \\
\hline $\begin{array}{l}\text { FLAT } \\
\text { DOSE } \\
\text { STRATEGY }\end{array}$ & $+4,5 \%$ & $+€ 687.173,55$ & $€ 15.957 .696,88$ & $+4,5 \%$ & $+€ 480.639,01$ & $€ 11.161 .505,98$ \\
\hline $\begin{array}{l}\text { BODY } \\
\text { WEIGHT- } \\
\text { BASED } \\
\text { STRATEGY }\end{array}$ & $-9 \%$ & - € 1.374.347,10 & $€ 13.896 .176,23$ & $-9 \%$ & - € 961.278,03 & $€ 9.719 .588,94$ \\
\hline $\begin{array}{l}\text { HYBRID } \\
\text { STRATEGY }\end{array}$ & $-11,6 \%$ & $-€ 1.771 .380,71$ & $€ 13.499 .142,63$ & $-11,6 \%$ & $\begin{array}{l}-€ \\
1.238 .980,57\end{array}$ & $€ 9.441 .886,40$ \\
\hline
\end{tabular}

Table V. Nivolumab expense data, with 2 different hypotheses of reduction in the drug price.

tients, confirming the aforementioned result (table II). Considering that the current price of nivolumab in Italy is $€ 7.69 / \mathrm{mg}$, the total amount saved with the hybrid strategy could allow purchasing 331.475,18 mg of additional drug. Considering the median administration dose reported in our analysis at Umberto I Hospital, this amount of nivolumab could cover 1423 additional cycles (table IV).

A further reduction in the price of nivolumab would not change the results of our study. Assuming the hypothesis of a $30 \%$ price reduction of nivolumab from $€ 7,69$ to $€ 5,39$ per $\mathrm{mg}$ (scenario I, table $\mathbf{V}$ ), the results would not differ from the baseline analysis. Considering an expense data of $€ 15.270 .523,33$ for real scenario, hybrid strategy could save $€ 1.771 .380,71$, which was about $3 \%$ less than the expense with the body weight-based dose. In the scenario II ( $€ 3,77$ per mg of nivolumab), flat dose strategy was the most expensive one and the other two strategies were more advantageous with few differences (table V). Thus, we can assume that the results observed in our analysis are valid and stable even if the price of nivolumab changes. Hybrid strategy was the most-cost effective in every alternative scenario of sensitivity analysis, giving robust and reproducible finding.
The second sensitivity analysis evaluated the variability of patients' body weight. We hypothesized a reduction of $5 \%$ of patient's weight in scenario III and an increase of $5 \%$ in scenario IV (table VI). In both scenarios III and IV, hybrid strategy was the most convenient. For instance, it reduced the spending of $8,9 \%$ in scenario III, which corresponded to a saving of $€ 1.957 .225,94$ in 1000 patients. In flat-dose strategy, the total cost did not change because the amount of drug administered did not depend on body weight. These data were consistent with the results of our analysis, showing also an increase in savings with lower patients' body weight. Therefore, the results of our study are robust even when the nivolumab price and patient's body weight change, and the hybrid strategy is confirmed the most cost-effective.

\section{DISCUSSION}

According to our analysis, the highest savings using different nivolumab schedules can be achieved with the hybrid strategy, and secondly with the body weight-based strategy. These approaches could allow 


\begin{tabular}{|c|c|c|c|c|c|c|}
\hline & \multicolumn{3}{|c|}{ + $5 \%$ OF BODY WEIGHT } & \multicolumn{3}{|c|}{ - 5\% OF BODY WEIGHT } \\
\hline & $\begin{array}{c}\Delta \% \\
\text { (COMPARED } \\
\text { TO REAL } \\
\text { SCENARIO) }\end{array}$ & $\begin{array}{c}\Delta \mathrm{N} \\
\text { (COMPARED TO } \\
\text { REAL SCENARIO) }\end{array}$ & $\begin{array}{l}\text { NIVOLUMAB } \\
\text { EXPENSE DATA } \\
\text { (SCENARIO III) } \\
\text { IN } 1000 \\
\text { PATIENTS }\end{array}$ & $\begin{array}{c}\Delta \% \\
\text { (COMPARED } \\
\text { TO REAL } \\
\text { SCENARIO) }\end{array}$ & $\begin{array}{c}\Delta \mathbf{N} \\
\text { (COMPARED TO } \\
\text { REAL SCENARIO) }\end{array}$ & $\begin{array}{l}\text { NIVOLUMAB } \\
\text { EXPENSE DATA } \\
\text { (SCENARIO IV) } \\
\text { IN } 1000 \\
\text { PATIENTS }\end{array}$ \\
\hline $\begin{array}{c}\text { REAL } \\
\text { SCENARIO }\end{array}$ & - & - & $€ 21.991 .302,73$ & - & - & $€ 21.641 .058,18$ \\
\hline $\begin{array}{l}\text { FLAT DOSE } \\
\text { STRATEGY }\end{array}$ & $+3,7 \%$ & $+€ 813.678,20$ & $€ 22.804 .980,93$ & $+5,4 \%$ & $\begin{array}{l}+€ \\
1.168 .617,14\end{array}$ & $€ 22.809 .675,32$ \\
\hline $\begin{array}{l}\text { BODY } \\
\text { WEIGHT- } \\
\text { BASED } \\
\text { STRATEGY }\end{array}$ & $-5 \%$ & - € 1.099.565,14 & $€ 20.891 .737,59$ & $-12,8 \%$ & - € 2.770.055,45 & $€ 18.871 .002,73$ \\
\hline $\begin{array}{l}\text { HYBRID } \\
\text { STRATEGY }\end{array}$ & $-8,9 \%$ & - € 1.957.225,94 & $€ 20.034 .076,78$ & $-14,8 \%$ & - $€ 3.202 .876,61$ & $€ 18.438 .181,57$ \\
\hline
\end{tabular}

Table VI. Nivolumab expense data, with 2 different hypotheses of mean patients' body weight.

an absolute reduction of required amount of drug (mg), and consequently an absolute reduction of costs compared to the real scenario. Our results showed a potentially remarkable cost saving in our centre during the period examined. Nevertheless, our simulations showed an absolute saving of $€ 2.549 .044,15$ per 1000 patients $(11,7 \%$ less than the cost of nivolumab in the real scenario) adopting a hypothetical hybrid strategy and an absolute saving of $€ 1.960 .803,19$ ( $9,0 \%$ less than the real scenario) by the hypothetical use of a body weight-based dose strategy during the observation period. Whereby, the flat-dose strategy led to an increased cost. These findings are consistent with the results of the few studies available nowadays in literature about the impact of drug dosing on the costs in the immunotherapy setting (20-23). In particular, a pharmacoeconomic analysis conducted in the US in 2017 pointed out that the body weight-based strategy ensured a significant cost saving compared to flat-dose strategy, with similar safety and efficacy (24). In the European setting, a retrospective observation on small Italian population in 2019 came to the same conclusions (19). The results achieved are also supported by the inclusion of drug wastes into the calculations. We observed that even considering the costs of drug waste per each administration, the hybrid strategy remained the most cost-effective approach, with an absolute saving of $€ 2.409 .917,83$ per 1000 patients ( $11,0 \%$ less than the real scenario).

Furthermore, our study showed that minimizing costs with drug day, vial sharing and dose rounding strategies allows a reduction of the drug waste and a further increase of the economic saving ensured by the hybrid strategy. These strategies minimized the drug left unutilized, thus drug waste could be considered close to zero. Our results corroborate the findings of similar experiences of other centres (25-27). In particular, an Italian multicentre study published in 2018 highlighted that the costs of immunotherapy treatments were inferior in the hospitals where a drug day strategy was been routinely applied (27). Therefore, if we regard that hybrid strategy with cost minimization systems could save $€ 2.549 .044,15$ per 1000 patients, considering the current price of nivolumab in Italy, we could purchase about $331.475,18 \mathrm{mg}$ of additional drug. These data are very meaningful, because, assuming this magnitude of costs saving and the mean dose administered in our center, we could have administered 1423 further cycles of nivolumab during the observed period.

Another strong point of the present analysis is the consistence of results, confirmed by the sensitivity analyses. The hybrid strategy was the most advantageous approach regardless of patient's body weight and decreasing in nivolumab price. This last issue could be a very probable eventuality for the coming years, due the many therapeutic indications of nivolumab. These results were consistent in all the hypothesized scenarios, considering either gross costs and waste-adjusted costs, and even modifying all the variables included in sensitivity analyses. Conversely, flat-dose was reconfirmed the most disadvantageous even varying those parameters. Therefore, the results are robust and the hybrid scenario is confirmed the most cost-effective. Definitely, the decreasing cost, waste-minimizing and sensitivity anal- 
yses mentioned above strengthen the validity and robustness of the economic evaluations presented. Nevertheless, the analysis has some weaknesses. The main limitation of the present study lies in the exiguity of the sample size. We selected a small sample, that not necessarily is representative of larger populations. Instead, only three cancer types were considered in the analyses of Mauriziano Umberto I Hospital. This restriction leads to several consequences. First of all, the small numerosity prevent us from drawing conclusions concerning safety and efficacy outcomes of the different schedules and strategies mentioned, and concerning a comparison between them. Nevertheless, the plenty of evidences regarding this topic available in the literature partially obviate this issue: several trials have shown the comparable efficacy and safety profile between the flat-dose and the body weight-based dose of nivolumab in advanced RCC, NSCLC and HNSCC $(14,15,28)$. So, every consideration in our analysis rely on this assumption. Moreover, it is critical to highlight that the present study was not designed with the purpose of investigate efficacy and safety outcomes.

Furthermore, because of the small sample size it is hard to evaluate appropriately a significant economic impact of these strategies in a large-scale. However, a study conducted in the US in 2018 showed the efficacy of dose rounding strategy even in medical centres caring less than 100 patients per year (29). Therefore, despite these limitations, the economic savings observed could be considered significant. Then, our evaluation did not include variations in the real cost of nivolumab for single Italian regions and single hospitals, beyond the official price, and did not include the whole spectrum of direct charges for the National health service (including the costs of clinical visit and follow-up, and the time for drug preparation and administration) and of indirect charges burdening on the patients (including the travel costs and the economic implications of lost working days). A more complete and exhaustive analysis should include the evaluation of all these factors, but nonetheless this issue does not affect the validity of the results, because the number of visits is the same for the different doses considered in the models, and the extra costs mentioned above can be considered relatively negligible when compared to nivolumab price.

Definitely, the present study shows impressive results, even if the analysis was restricted to few cancer types. These findings must impel us to explore these strategies in the widest possible setting. It is impor- tant to emphasize that even if the validity of these results could be potentially extended to other European healthcare systems, further analyses are required regarding to different contexts. Actually, there is a remarkably huge variability between different healthcare systems in terms of economic factors: different treatment setting of day hospital or hospitalization regimen, different organization of the healthcare facilities, availability of different size of vials, different number of patients treated (30). By the way, there is a clear advantage in exploring the above-mentioned strategies in all the European healthcare systems.

\section{CONCLUSIONS}

The present study highlights the relevant economic savings potentially associated with the introduction of hybrid strategy in the setting of nivolumab therapy compared to the current standard flat-dose schedule. Furthermore, the study shows the remarkable economic impact in terms of oncologic therapies cost reduction through the use of waste minimization policies, such as dose rounding and drug day strategies. The present analysis provides also a possible perspective of economic implications and impact of a similar strategy on a larger scale. In a landscape of rising costs of health care and of new anti-cancer drug discovery, especially concerning to future implementation of nivolumab and other immune-checkpoint inhibitors, it will be essential to identify and adopt strategies of costs minimization. In accordance with the results of the present analysis, the whole system would benefit if the hybrid strategy replaces the flat dose for all cancer patients in treatment with nivolumab. Moreover, vial sharing and dose rounding should be implemented whenever possible.

\section{ETHICS}

\section{Fundings}

There were no institutional or private fundings for this article.

\section{Conflict of interests}

The authors have declared no conflict of interests.

\section{Availability of data and material}

The data underlying this article can be shared just before a reasonable request to the corresponding author. 


\section{Code availability \\ N/A}

\section{Authors' contribution}

Conception and design: TG, AC, FS, CP, GF, MDM. All authors have made substantial contributions to acquisition of data, analysis and interpretation of data.
All authors have been involved in drafting the manuscript or revising it critically for important intellectual content, and all authors have given final approval of the version to be published

\section{Ethical approval}

N/A

\section{REFERENCES}

1. Pardoll DM. The blockade of immune checkpoints in cancer immunotherapy. Nat Rev Cancer 2012;12(4):252-64.

2. Brahmer J, Reckamp KL, Waterhouse D, et al. Nivolumab versus docetaxel in advanced squamous-cell non-small-cell lung cancer. N Engl J Med 2015;373(2):123-35.

3. Borghaei $H$, Paz-Ares L, Barlesi F, et al. Nivolum$a b$ versus docetaxel in advanced nonsquamous non-small-cell lung cancer. $\mathrm{N}$ Engl J Med 2015;373(17):1627-39.

4. Motzer RJ, EscudierB, Castellano D, etal. Nivolumab versus everolimus in advanced renal-cell carcinoma. N Engl J Med 2015;373(19):1803-13.

5. Ferris RL, Blumenschein JG, Worden F, et al. Nivolumab for recurrent squamous-cell carcinoma of the head and neck. $N$ Engl J Med 2016;375(19):1856-67.

6. Gazzetta Ufficiale Serie Generale n. 224 del 2609-2018. Regime di rimborsabilità e prezzo del medicinale per uso umano «Opdivo». Determina n. 1403/2018. (18A06153).

7. Weber JS, D'Angelo SP, Minor D, et al. Nivolumab versus chemotherapy in patients with advanced melanoma who progressed after anti-CTLA-4 treatment (CheckMate 037): a randomised, controlled, open-label, phase 3 trial. Lancet Oncol 2015;16(4):375-84.

8. Topalian SL, Hodi FS, Brahmer JR, et al. Safety, activity, and immune correlates of anti-PD-1 antibody in cancer. N Engl J Med 2012;366(26):2443-54.

9. Agrawal S, Feng Y, Roy A, Kollia G, Lestini B. Nivolumab dose selection: challenges, opportunities, and lessons learned for cancer immunotherapy. J immunother Cancer 2016;4(1):72.

10. Zhao, X, Ivaturi, V, Gopalakrishnan, M. Abstract CT101: a model-based exposure-response (ER) assessment of a nivolumab (NIVO) 4-weekly (Q4W) dosing schedule across multiple tumor types. Cancer Res 2017;77 (Suppl 13). Doi: 10.1158/1538-7445.AM2017-CT101.

11. Chatterjee M, Turner DC, Flotten O, et al. Systematic evaluation of pembrolizumab dosing in patients with advanced non-small cell lung cancer. Annal Oncol 2016;27(7):1291-8.

12. Novakovic AM, Wilkins JJ, Dai H, et al. Changing Body Weight-Based Dosing to a Flat Dose for Avelumab in Metastatic Merkel Cell and Advanced Urothelial Carcinoma. Clin Pharmacol Ther 2020;107(3):588-96.

13. Freshwater T, Kondic A, Stone JA et al. Evaluation of dosing strategy for pembrolizumab for oncology indications. J Immunother Cancer 2017;5:43.

14. A. Zhao X, Suryawanshi S, Hruska M, et al. Assessment of nivolumab benefit-risk profile of a 240-mg flat dose relative to a 3-mg/kg dosing regimen in patients with advanced tumors. Ann Oncol 2017;28(8):2002-8.

15. Feng $Y$, Wang $X$, Roy $A$, et al. Nivolumab exposure-response analyses of efficacy and safety in previously treated squamous or nonsquamous non-small cell lung cancer. Clin Cancer Res 2017;23(18):5394-405.

16. Bajaj G, Wang X, Agrawal S, Gupta M, et al. Model-Based Population Pharmacokinetic Analysis of Nivolumab in Patients With Solid Tumors. CPT Pharmacometrics Syst Pharmacol 2017;6(1):58-66.

17. Bellesoeur E, Ollier MA, Blanchet B, et al. Is there an Exposure-Response Relationship for Nivolumab in Real-World NSCLC Patients? Cancer 2019;11(11):1784.

18. Goldstein D. Weight-based dosing vs fixed dosing of pembrolizumab: an economic analysis. Clin Adv Hematol Oncol 2018;16(8):549-51.

19. Giuliani J, Albanese V, Ponturo G, Bonetti A. Economic sustainability of nivolumab at flat dose for second-line treatment of metastatic non-small cell lung cancer in real life. J Oncol Pharm Pract 2019;25(8):2059-60.

20. Bayle A, Besse B, Annereau M, Bonastre J. Switch to anti-programmed cell death protein 1 
(anti-PD-1) fixed-dose regimen: what is the economic impact?. Eur J Cancer 2019;113:28-31.

21. Hall E, Zhang J, Kim EJ, Hwang G, Chu G, Bhatia S, Reddy S. Economics of alternative dosing strategies for pembrolizumab and nivolumab at a single academic cancer center. Cancer Med 2020;9(6):2106-12.

22. De Lemos ML, Kung C, Waignein S. Efficacy of nivolumab four-weekly dosing schedule based on body weight. J Oncol Pharm Pract 2019;25(4):961-3.

23. Goldstein DA, Ratain MJ, Saltz LB. WeightBased dosing of pembrolizumab every 6 weeks in the time of COVID-19. JAMA Oncol 2020;6(11):1694-5.

24. Goldstein DA, Gordon N, Michal Davidescu M, et al. A phamacoeconomic analysis of personalized dosing vs fixed dosing of pembrolizum$a b$ in firstline PDL1-positive Non-Small Cell Lung Cancer. J Natl Cancer Inst 2017;109(11).

25. Hess LM, Cui ZL, Li Xl, Oton AB, Shortenhaus $\mathrm{S}$, Watson IA. Drug wastage and costs to the healthcare system in the care of patients with non-small cell lung cancer in the United States.
J Med Econ 2018;21(8):755-61.

26. Fasola G, Aita LM. Drug waste minimisation and cost-containment in Medical Oncology: two-year results of a feasibility study. BMC Health Serv Res 2008;8:70.

27. Damuzzo V, Russi A, Chiumente M, Masini C, et al. Optimization of resources by drug management: a multicentred web-administered study on the use of ipilimumab in Italy. J Oncol Pharm Pract 2018;25(4):787-92.

28. Kato R, Ikarashi $D$, et al. Analyses of nivolumab exposure and clinical safety between 3-mg/ $\mathrm{kg}$ dosing and 240-mg flat dosing in Asian patients with advanced Renal Cell Carcinoma in the real-world clinical setting. Transl Oncol 2020;13(6):100771.

29. Chillari KA, Southward J, Harrigan N. Assessment of the potential impact of dose rounding parenteral chemotherapy agents on cost savings and drug waste minimization. J Oncol Pharm Pract 2018;24(7):507-10.

30. Buxton MJ, Drummond MF, Van Hout BA, et al. Modelling in ecomomic evaluation: an unavoidable fact of life. Health Econ 2017;(3):217-27. 